\title{
High functional complexity despite an extremely small repertoire of calls in the Spotted Crake (Porzana porzana)
}

Author(s): Paweł Ręk

Source: The Auk, 132(3):613-623.

Published By: The American Ornithologists' Union

DOI: http://dx.doi.org/10.1642/AUK-14-267.1

URL: http://www.bioone.org/doi/full/10.1642/AUK-14-267.1

BioOne (www.bioone.org) is a nonprofit, online aggregation of core research in the biological, ecological, and environmental sciences. BioOne provides a sustainable online platform for over 170 journals and books published by nonprofit societies, associations, museums, institutions, and presses.

Your use of this PDF, the BioOne Web site, and all posted and associated content indicates your acceptance of BioOne's Terms of Use, available at www.bioone.org/page/terms_of_use.

Usage of BioOne content is strictly limited to personal, educational, and non-commercial use. Commercial inquiries or rights and permissions requests should be directed to the individual publisher as copyright holder. 


\title{
High functional complexity despite an extremely small repertoire of calls in the Spotted Crake (Porzana porzana)
}

\author{
Paweł Ręk \\ Department of Behavioral Ecology, Institute of Environmental Biology, Faculty of Biology, Adam Mickiewicz University, Poznań, \\ Poland \\ Division of Evolution, Ecology and Genetics, Research School of Biology, Australian National University, Canberra, Australia \\ rek@amu.edu.pl
}

Submitted November 19, 2014; Accepted March 4, 2015; Published May 13, 2015

\begin{abstract}
Vocal learning and nonlearning birds frequently use the same habitats and are subject to similar selection pressures. However, although the repertoires of learning species are usually more complex, we know much less about how nonlearners encode information in acoustic signals. The present study describes the use of 3 basic mechanisms of acoustic encoding in signals of a vocal nonlearner: in repertoire, in acoustic structure, and in the temporal distribution of sounds. The study is based on observations of a simulated territorial intrusion in the Spotted Crake (Porzana porzana), a cryptic rail from Western and Central Eurasia. Males produced 5 types of calls. The loudest, the whitt call, consisted of 2 independent sounds with different fundamental frequencies: a soft and low $F$ call and a loud and high $G$ call. Before the playback, all males produced calls that consisted of both frequencies ( $F+G$ calls), and most of the birds still produced such calls after the playback. Only birds that approached the speaker during the playback produced $\mathrm{F}$ calls, F+G calls with a muffled $\mathrm{G}$ fundamental, and structurally distinctive soft rumble calls, whereas only birds that did not approach the speaker used $G$ calls. These data suggest that males' engagement in aggressive interaction was associated with muting $G$ or $F$ fundamentals. The acoustic structure of whitt calls varied significantly between preplayback and postplayback recordings, and between approaching and nonapproaching males. However, certain acoustic parameters retained a high potential for individual recognition despite the playback. Finally, males lengthened their between-call intervals as they approached the speaker, which suggested that there was a link between the temporal distribution of calls and the aggressive motivation of males. Although they have a small repertoire of calls with innately programmed structures, Spotted Crakes modify their calling on many different planes and produce a high diversity of signals.

Keywords: aggressive motivation, coding scheme, fundamental frequency, Porzana porzana, signal function, soft calls, soft songs, Spotted Crake
\end{abstract}

\section{Grande complexité fonctionnelle malgré un très petit répertoire des cris chez Porzana porzana RÉSUMÉ}

Les oiseaux qui font un apprentissage vocal et ceux qui n'en font pas utilisent fréquemment les mêmes habitats et sont assujettis à des pressions de sélection similaires. Toutefois, bien que les répertoires des espèces qui apprennent soient habituellement plus complexes, nous en savons beaucoup moins sur la façon dont celles qui ne font pas d'apprentissage vocal codifient l'information en des signaux acoustiques. Cet article décrit l'utilisation de trois mécanismes de base de codification acoustique en des signaux chez une espèce qui ne fait pas d'apprentissage vocal : dans le répertoire, dans la structure acoustique et dans la distribution temporelle des sons. L'étude est basée sur les observations d'une intrusion territoriale simulée chez Porzana porzana, un râle cryptique de l'ouest et du centre de l'Eurasie. Les mâles ont produit cinq types de cris. Le plus sonore, le whitt, consistait en deux sons indépendants avec des fréquences fondamentales différentes : un $\mathrm{F}$ doux et grave et un $g$ sonore et aigu. Avant la repasse d'enregistrements, tous les mâles ont produit des cris composés des deux fréquences $(\mathrm{F}+\mathrm{G})$ et la plupart des oiseaux produisaient encore ces cris après la repasse d'enregistrements. Seuls les oiseaux qui s'approchaient du haut-parleur au cours de la repasse d'enregistrements ont produit des $\mathrm{F}$, des $\mathrm{F}+\mathrm{G}$ avec un $\mathrm{g}$ fondamental étouffé ainsi qu'un ronronnement doux structurellement distinctif, alors que seuls les oiseaux qui ne se sont pas approchés du haut-parleur ont émis des $\mathrm{G}$. Ces données suggèrent que l'engagement des mâles dans une interaction agressive était associé à la mise en sourdine des $G$ ou $F$ fondamentaux. La structure acoustique du whitt variait significativement entre les enregistrements avant et après la repasse d'enregistrements, et entre les mâles qui s'approchaient et ceux qui ne s'approchaient pas. Toutefois, certains paramètres acoustiques contenaient un grand potentiel pour la reconnaissance individuelle malgré la repasse d'enregistrements. 
Enfin, les mâles allongeaient l'intervalle entre les cris lorsqu'ils s'approchaient du haut-parleur, ce qui suggère qu'il existait un lien entre la distribution temporelle des cris et la motivation agressive des mâles. Bien qu'il ait un petit répertoire de cris avec des structures programmées innées, $P$. porzana modifie ses cris sur plusieurs plans et produit une grande diversité de signaux.

Mots-clés: chants doux, cris doux, fonction de signal, fréquence fondamentale, motivation agressive, Porzana porzana, schéma de codage

\section{INTRODUCTION}

The design of bird acoustic signals is the result of the influence of different selection pressures within limits framed by phylogeny (ten Cate 2004). Passerine birds, for example, produce large repertoires of learned songs, and the ability to acquire new sounds appears to be more than adequate to meet their communication requirements. By contrast, in a majority of other groups of birds, the repertoires of songs or calls are relatively small and static during a lifetime. One reason for this stasis is the various physiological limitations of the respiratory, phonatory, and filter systems in different phylogenetic groups (Janik and Slater 2000). Although the acoustic systems of learners and nonlearners are subject to similar selective pressures, and although the species in the 2 groups frequently inhabit the same habitats, we know much less about how nonlearners encode information in small repertoires of vocalizations.

Birds use 3 basic mechanisms of information encoding in acoustic signals: in the song or syllable repertoire (Searcy et al. 1999), in modifications of the acoustic structure of sounds of a specific type (Dabelsteen and Pedersen 1990, Slabbekoorn and ten Cate 1998), and within the temporal distribution of sound elements (Freeberg and Lucas 2002, Ręk and Osiejuk 2013). The use of different vocalizations to transmit referential information has been suggested for various mammals and a few species of learning and nonlearning birds, including Red Junglefowl (Gallus gallus) and Siberian Jay (Perisoreus infaustus) (Evans and Evans 2007, Griesser 2008). The first mechanism involves birds, particularly open-ended learners, also using the complexity of repertoires to produce intersexual signals of quality (Darolová et al. 2012); and in certain passerines (e.g., Song Sparrow [Melospiza melodia]), repertoire matching is associated with different levels of aggression (Beecher et al. 1996). The second mechanism involves simple changes in frequency and amplitude within vocalizations or the inclusion of particular notes within songs. This may be a universal mechanism of information encoding in acoustic signals; it is used by vertebrates and by many groups of invertebrates. Among songbirds, different frequency components of sounds are used for neighbor-stranger discrimination by, for example, Ortolan Buntings (Emberiza hortulana; Osiejuk 2014); frequency matching is used during interactions with intruders by Black-capped Chick- adees (Poecile atricapillus; Foote et al. 2008); and variation in song amplitude between males has been linked to social aggression in Common Chaffinches (Fringilla coelebs; Brumm and Ritschard 2011). Similarly, stable amplitude modulation and distribution of formant frequencies are potentially individuals' fingerprints in the Corn Crake (Crex crex), a nonlearning species (Budka and Osiejuk 2013a, 2013b). Moreover, both learning and nonlearning birds produce loud and soft variants of vocalizations in different contexts (Dabelsteen et al. 1998, Ręk and Osiejuk 2011). With the third mechanism, temporal distribution, animals have the potential to increase the range of information by combining vocalizations in different ways, and this mechanism pertains to 2 different coding schemes. Birds may communicate by recombining different vocalizations, which was suggested for Carolina Chickadees (P. carolinensis; Freeberg and Lucas 2002), or by separating similar vocalizations with silent intervals of different lengths; however, this second coding scheme of using the temporal arrangement of single call types has been the focus of relatively few studies (Ręk and Osiejuk 2010, 2013).

Acoustic communication in the Rallidae is a good model for studying coding schemes in acoustic signals because rails have relatively small repertoires of innate calls, as is true of most nonpasserine birds. Many rails produce long series of calls with a specific temporal and structural organization. Such repetitive calling creates many possibilities for information encoding, but this behavior has been studied in detail in only a single species, the Corn Crake (Ręk and Osiejuk 2013), in which the temporal pattern of calls is a signaling system based on syntax. In this system, information about a male's aggressive motivation is encoded in sequences of similar vocalizations that are separated alternately by long and short intervals. Additionally, Corn Crakes produce soft calls during aggressive encounters with rivals (Ręk and Osiejuk 2011), analogous to the soft songs produced by certain passerines (Dabelsteen et al. 1998, Hof and Hazlett 2010, Anderson et al. 2012). Many similar soft vocalizations have been mentioned for other rail species. Thus, 2 possible generalizations are emerging: The first concerns the specific role of temporal encoding in rails, and the second concerns the common role of soft vocalizations in birds.

Here, I describe the call structure, repertoire, temporal organization, and variation of these parameters during 
territorial intrusion in a rail species, the Spotted Crake (Porzana porzana). Like many cryptic rails, the Spotted Crake is known primarily for its long series of almost identical whitt calls; however, little is known about the structural variability, temporal organization, and function of this call, and even less is known about the various call types (Cramp and Simmons 1980). Spotted Crakes and Corn Crakes are sympatric and phylogenetically closely related species (Livezey 1998), with Spotted Crakes preferring marshy areas. Both species are territorial when breeding and are aggressive toward intruders. Therefore, by simple analogy, some type of functional variability in the temporal distribution of the Spotted Crake's calls associated with the aggressive motivation of the caller might be expected. By contrast, the acoustic structure of the Spotted Crake's whitt calls does not resemble the territorial calls of the Corn Crake. The Corn Crake's calls do not change during territorial intrusion, but they have a high potential for individual recognition (Budka and Osiejuk 2013a, 2013b). Information on whether and how these differences are reflected in the functional complexity of the Spotted Crake's calls might broaden our understanding of acoustic encoding in relatively simple systems. Finally, the use of low-amplitude calls by Spotted Crakes is described and analyzed to provide a strong case for a more general conclusion about the role of soft vocalizations in the context of territorial aggressive interactions.

\section{METHODS}

\section{Study Site and Species}

The study was conducted in Kampinoski National Park, Poland $\left(20^{\circ} 23^{\prime} \mathrm{E}\right.$ and $\left.52^{\circ} 19^{\prime} \mathrm{N}\right)$, and in surrounding areas during May 5-20, 2014. The subjects were 26 territorial male Spotted Crakes, which at that time were the entire calling population in the area. Most males called almost continually throughout the night, and their territories were sparsely distributed. The shortest distance between 2 simultaneously calling males was $142 \mathrm{~m}$ (distance between the nearest global positioning system [GPS] coordinates of males; mean $\pm \mathrm{SD}=539 \pm 262 \mathrm{~m}$ ); however, in most cases, males called too far away from conspecifics to hear them. Because breeding males are silent, singing activity is a good indicator of a male's breeding stage (Cramp and Simmons 1980). Hence, it is probable that the study was conducted during territory establishment with still unmated males, the time of the most aggressive competition between individuals.

Spotted Crake is a small (19-24 cm in length), secretive, and migratory species, belonging to those rails that are easy to hear but very hard to see. In breeding areas across temperate Europe and in western Asia, Spotted Crakes inhabit marshes and sedge beds with shallow water and nest in dry locations in marsh vegetation; however, they avoid submerged areas, the habitat of sympatric Water Rails (Rallus aquaticus), and dry grasslands, which are preferred by sympatric Corn Crakes.

\section{Playback Experiment}

I conducted a playback experiment to examine the behavior of receivers resulting from territorial intrusion; however, the experiment did not test the function of the calls used in the playbacks. Therefore, playback samples were not modified structurally or temporally. Additionally, the samples did not contain different call types, because they were not intended to threaten a subject or stimulate it in any specific way but only to imitate the presence of an intruder within the subject's territory.

\section{Preparation of Call Stimuli}

Territorial whitt calls for playbacks were recorded from 26 different males during each May for 3 yr (2010-2012) in the same area, using a handheld directional microphone (Sennheiser ME67) 15-20 m from the subjects. Both study and recording areas covered $\sim 200 \mathrm{~km}^{2}$, and the GPS positions of recording of call samples and their playback were spatially isolated by $\geq 11 \mathrm{~km}$. Therefore, it was unlikely that call samples used for the study were of males with which the study subjects had previous interactions. The calls were digitized using the Avisoft SASLab Pro 5.2 sound analysis package (Avisoft Bioacoustics, Glienicke, Germany; $48 \mathrm{kHz}$ and 16-bit PCM files). Each playback sample was high-pass filtered $(100 \mathrm{~Hz})$ to remove all irrelevant low-frequency noise and was trimmed to a 3min fragment and prepared to match a $93-\mathrm{dB}$ value in the field (sound pressure level [SPL] at $1 \mathrm{~m}$ ). The amount of call playback was standardized across subjects. Because the rates of calls in uninterrupted sequences were very similar among recordings (65-71 calls $\mathrm{min}^{-1}$ ), it was always possible to frame a fragment of a recording with $69 \pm 2$ calls $\mathrm{min}^{-1}$. The SPL value was set according to the amplitude level of a typical Spotted Crake whitt call as previously measured in the field with a UT352-Sinometer sound pressure level meter.

\section{Experimental Protocol}

I played back 26 call samples to 26 territorial males and recorded their calling and behavior. The trials were conducted between 2200 and 0230 hours local time, which corresponded to the peak nocturnal vocal activity of the Spotted Crakes. In order to standardize the positions of the speaker within territories of males, the GPS positions of calling males were collected $\geq 1$ day before the planned playback. The playback was conducted only if a male was calling from the same spot as the day before $( \pm 20 \mathrm{~m})$. If not, a new GPS position was collected and playback was postponed to the next day. Because most of the males were calling from the same spots, even for weeks, and most of 
TABLE 1. Descriptions of variables used in sound analyses of 26 male Spotted Crakes recorded in May, 2014, in Kampinoski National Park, Poland, and surrounding areas.

\begin{tabular}{|c|c|c|}
\hline Variable & Description & Range \\
\hline Tip duration & Duration of the initial part of $\mathrm{G} 1$ & $0.007-0.058 \mathrm{~s}$ \\
\hline$t(\min -\max )$ & $\begin{array}{l}\text { Time between the lowest and } \\
\text { highest frequencies of } \mathrm{G} 2\end{array}$ & $0.046-0.116 \mathrm{~s}$ \\
\hline$t($ peak-min) & $\begin{array}{l}\text { Time between the lowest and } \\
\text { peak frequencies of } G 2\end{array}$ & $0.011-0.081 \mathrm{~s}$ \\
\hline Freq. min. & Lowest frequency of G2 & $1,280-2,130 \mathrm{~Hz}$ \\
\hline Freq. max. & Highest frequency of G & $3,430-5,610 \mathrm{~Hz}$ \\
\hline Freq. peak & $\begin{array}{l}\text { Frequency of maximum } \\
\text { amplitude (always G2) }\end{array}$ & $1,840-3,490 \mathrm{~Hz}$ \\
\hline Interval & $\begin{array}{l}\text { Interval between consecutive } \\
\text { calls ( } \mathrm{G} \text { calls or } \mathrm{F}+\mathrm{G} \text { calls) }\end{array}$ & $0.51-7.05 \mathrm{~s}$ \\
\hline
\end{tabular}

the relocations did not exceed $50 \mathrm{~m}$, calling spots were likely the cores of males' territories rather than the edges. Before each trial, a loudspeaker was placed $<0.5 \mathrm{~m}$ above the ground within the subject male's territory. Playback calls were broadcast from the shortest distance possible through an amplified loudspeaker ( $45 \mathrm{~W}$, frequency range 60-15,000 Hz; Mipro MA-101A) connected to a Creative ZEN player. I approached the males as long as their calling was not interrupted or until their positions could be relatively well assessed. In the second case, the approach was limited to $15 \mathrm{~m}$ from the male $(15-20 \mathrm{~m})$. At the same time, because Spotted Crakes walked rather than flew toward the playback speaker, the speaker was always placed in the same type of vegetation as the male. Each trial used a different sample of whitt calls, and the calls used in each trial came from a single male. Before the playback, a male was recorded for $\geq 1 \mathrm{~min}$. Each playback lasted $3 \mathrm{~min}$, and the recording continued for another 10 min. A directional microphone (Sennheiser ME67) connected to a Roland Edirol R-26 portable recorder was used to capture the recordings.

\section{Data Analyses}

The study used both behavioral data collected during trials and acoustic data extracted from audio recordings. According to their movement, the males were categorized into 2 groups: approachers, which were males that moved close to the speaker $(<3 \mathrm{~m})$ during or after the playback and were seen and/or heard walking near the speaker, and nonapproachers, which were males that stayed in a similar position before and after the playback. Because the distribution of the movement behavior in response to playback was strictly binomial among males, the classification was straightforward. If a bird fell silent during the playback, its movement was not classified until it started to call again, to ensure that it did not change its position; however, males walking near the speaker could easily be heard and located, irrespective of their calling.
From each individual, a sample was obtained of 10 highquality whitt calls recorded before the playback. Additionally, another 10 calls were recorded after the playback. Only the calls produced after the playback were used in bioacoustic analyses, because such calls did not overlap with playback calls and because approaching males did not sing while walking. Moreover, there is a possibility that the first involuntary reaction to playback may affect the posture of a listener and temporarily change the muscle activity of its vocal apparatus and the structure of the calls produced. To evaluate the between-call intervals, 2 continuous call sections from each male (which were recorded before and after the playback, with 8-19 calls $[$ mean $=13$ ] per section) were obtained from each male. The silent sections between calls (7-18 intervals section ${ }^{-1}$ ) were then measured. The sounds were analyzed with Avisoft SASLab Pro 5.2 (48 kHz and 16 bit PCM files). Prior to the analysis, the recordings were high-pass filtered $(100 \mathrm{~Hz})$ to remove all irrelevant low-frequency noise. At the same time, the remaining call types were counted. The following bioacoustic parameters are listed, defined, and illustrated in Table 1 and Figure 1. The magic cursor function of the sonogram window was used to measure the $t$ (min-max), freq. min., freq. max., $t$ (peak-min), and freq. peak parameters, whereas the tip duration was measured directly from the waveform. The general settings of the sonogram window were as follows: $\mathrm{FFT}=1,024$, frame size $(\%)=50$, Hann window, bandwidth $=141 \mathrm{~Hz}$, frequency resolution $=47 \mathrm{~Hz}$, and temporal resolution $=98.43$. These settings allowed measurements in the time domain with 0.333-ms accuracy. To minimize measurement error, time and frequency were sampled from the strongest second harmonic (G2), except for the tip duration, which was the strongest at the first harmonic (Figure 1). To measure intervals between whitt calls objectively, the waveformbased analysis of temporal patterns ("pulse train analysis") function was used. The "rectification + exponential decay" method for envelope detection was used, and each measurement of call distribution was visually checked to determine whether all calls were detected. In this method, the original waveform is first rectified and the resulting envelope follows the rectified waveform as long as the amplitude is rising. If the amplitude of the rectified waveform decreases, the most recent peak amplitude decays exponentially at a predefined time constant. Consequently, the small instantaneous amplitudes between consecutive waves are bridged. The pulse train analysis used the following settings: time constant $=1 \mathrm{~ms}$, hysteresis $=20 \mathrm{~dB}$, and start-end threshold $=-10 \mathrm{~dB}$, with hysteresis and threshold parameters controlling the peak detection.

For the analysis of the potential of acoustic parameters for individual recognition, I considered the calls recorded before and after the playback. I assumed that an effective set 


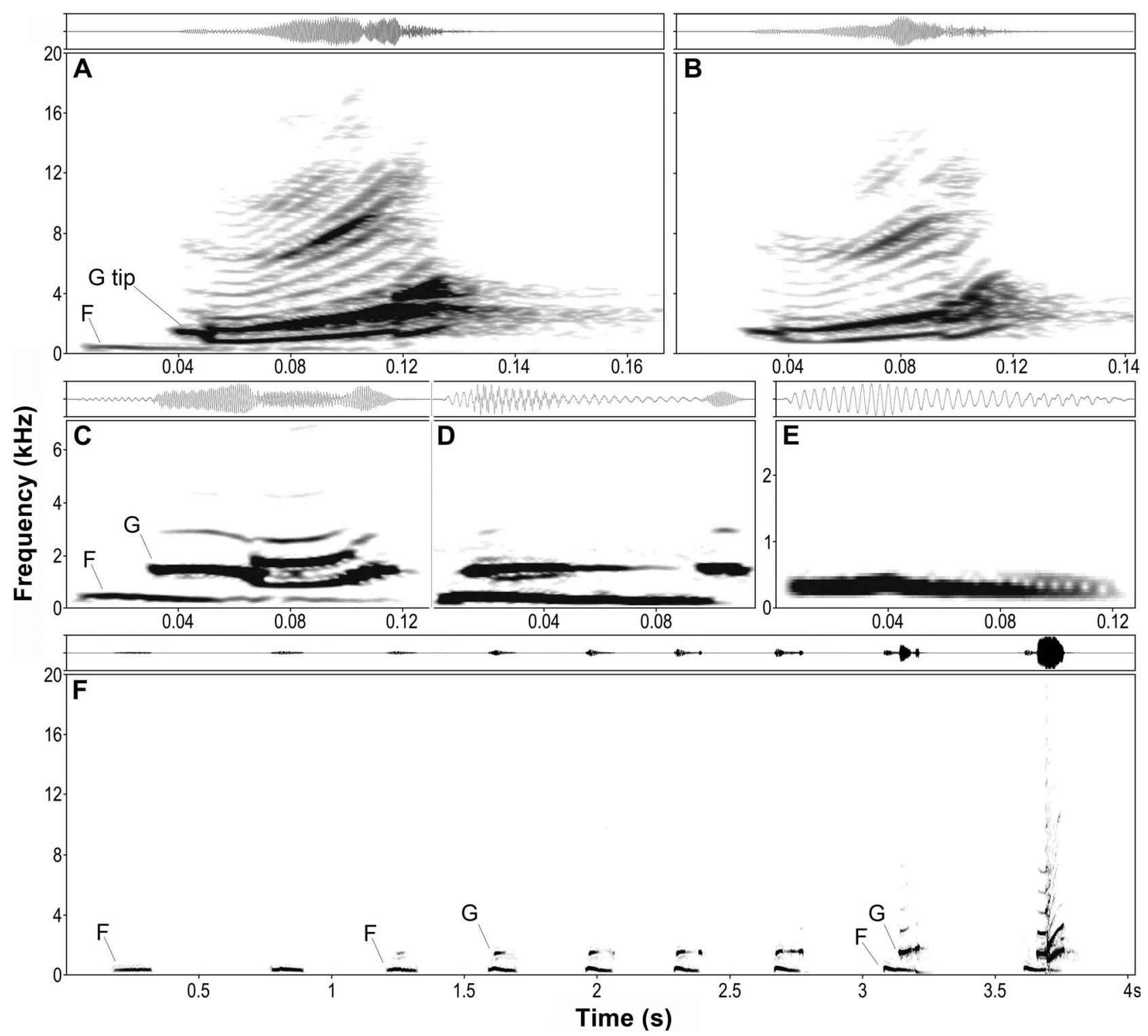

FIGURE 1. Sonograms and waveforms of calls of 26 male Spotted Crakes recorded in May, 2014, in Kampinoski National Park, Poland, and surrounding areas. (A) F+G call (full whitt call) with marked $F$ fundamental and the tip of $G$ fundamental. (B) $G$ call. (C, D) 2 examples of muffled whitt calls (muffled whitt $=\mathrm{F}+$ soft $\mathrm{G}$ ). (E) $\mathrm{F}$ call. (F) Process of transition between $\mathrm{F}$ call and $\mathrm{F}+\mathrm{G}$ call. The transition depicted in $\mathbf{E}$ is a natural series produced by 1 bird over a 4-s period. According to this progression, the first 2 calls would be classified as F calls, the last one as a full whitt call, and the remaining calls as muffled whitt calls. Amplitudes of waveforms and sonograms were standardized to the maximum values for each call; however, the amplitudes of calls measured from recordings in relation to the full whitt call were $\mathrm{G}$ call $=-1.7 \mathrm{~dB}$, muffled whitt calls $=-16.6$ and $-10.9 \mathrm{~dB}$, and $\mathrm{F}$ call $=-17.8 \mathrm{~dB}$.

of parameters for individual recognition would be highly resistant to external disturbance. Conversely, the use of calls recorded only before the playback might overestimate or underestimate the potential of the parameters.

\section{Statistics}

For the analysis of the frequency of different calls between approachers and nonapproachers, I used a Fisher's exact test $(\mathrm{df}=1)$. Linear mixed models were used for the analysis of the functional variation of calls. Within the models, the acoustic parameters (listed in Table 1) were dependent variables, whereas the male and experimental stage (prepost, i.e. before or after the playback) were used to build a covariance structure for the random factor. Additionally, approach behavior (yes-no) and the experimental stage (before-after) with interaction were used as fixed factors; however, the use of these factors in the final models depended on Akaike's Information Criterion (AIC). For the post hoc analyses, a Fisher's least significant difference test was used. 


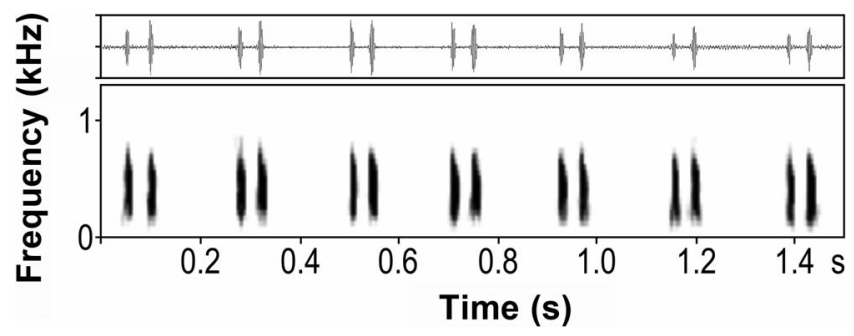

FIGURE 2. Sonogram and waveform of the rumble calls of 26 male Spotted Crakes recorded in May, 2014, in Kampinoski National Park, Poland, and surrounding areas. Amplitudes of waveforms and sonograms were standardized to the maximum values for each call; however, the amplitude of calls measured from recordings in relation to the full whitt call was between -31.2 and $-33.5 \mathrm{~dB}$. These calls make an uninterrupted series produced by 1 bird.

A discriminant function analysis (DFA) was used to classify the vocalizations according to the individual that had originally produced them. The following were used as independent discriminating variables: tip duration, $t(\mathrm{~min}-$ max), freq. min., freq. max., $t$ (peak-min), and freq. peak (for definitions, see Table 1). The independent variables were entered together in the DFA model, and a leave-oneout classification procedure was then used to examine the correctness of the classification. All analyses were conducted in SPSS version 21 (IBM, Armonk, New York, USA). All $P$ values are 2-tailed.

\section{RESULTS}

\section{Functional Diversity of the Repertoire}

Spotted Crakes produced 5 types of calls (Figures 1 and 2 ). The loudest whitt call was a combination of 2 independent elements with different fundamental frequencies (marked as F and G in Figure 1). These elements could be produced together as components of a single whitt call or separately as independent calls (Figure 1); however, all playback calls consisted of both F and G fundamentals. Additionally, males produced muffled whitt calls that consisted of an F call and a soft underdeveloped G call (Figure 1C, 1D), and structurally distinct, soft rumble calls (Figure 2).

Before the playback, all males produced calls that consisted of both F and G fundamentals; after the playback, their acoustic behavior changed, depending on the tactic used (Figure 3). Only birds that approached the playback speaker $(n=16)$ used F calls, muffled whitt calls, and rumble calls; and only birds that did not approach the speaker $(n=10)$ used G calls; but not all birds in each category produced those calls (Figure 3 ). The differences between the 2 groups of birds were significant for the muffled whitt calls (Fisher's exact test, $P=0.035$ ), G calls $(P=0.018)$, and rumble calls $(P=0.035)$. The difference

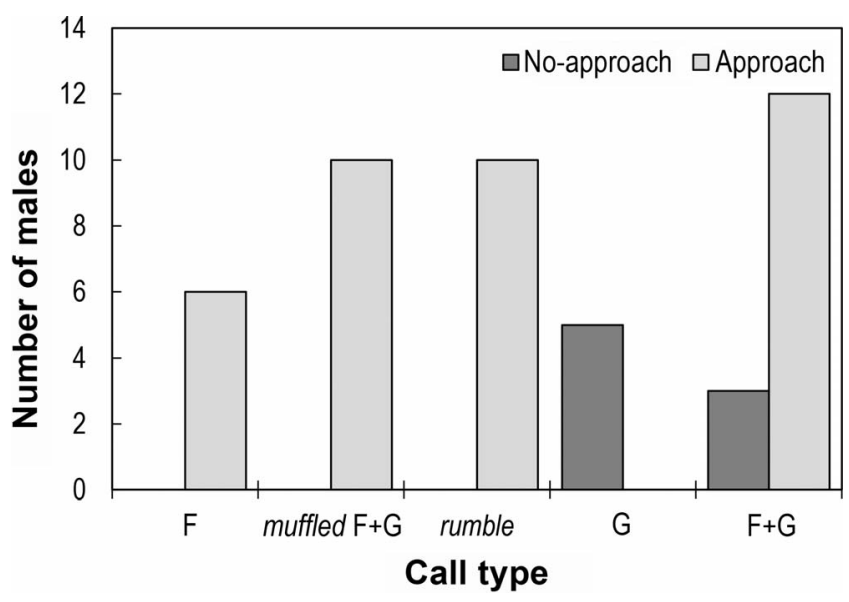

FIGURE 3. Approachers and nonapproachers among 26 male Spotted Crakes calling with different types of calls after playback, recorded in May, 2014, in Kampinoski National Park, Poland, and surrounding areas. Because most males produced several call types, the numbers from different call types do not produce the same totals. Before the playback, all males produced only $\mathrm{F}+\mathrm{G}$ calls.

between $\mathrm{F}$ callers in the 2 groups was not significant $(P=$ 0.142 ), but only approachers used F calls or muffled whitt calls, and 4 of $6 \mathrm{~F}$ callers also produced muffled whitt calls. Thus, when combined, the number of $\mathrm{F}$ or muffled whitt callers differed significantly between the 2 groups $(P=$ 0.016).

\section{Functional Variation of Whitt Calls}

The acoustic structure and temporal distribution of whitt calls varied significantly with reference to the simulated intrusion, the tactic used, or both. In total, 20 of 26 males that called before the playback called after the playback with G or F+G calls, and only these 20 males were used in the following analyses. Compared with the initial state, postplayback $\mathrm{G}$ calls were characterized by longer tips and shorter times between the lowest and highest frequencies. However, the effect of playback on the times between the lowest and highest frequencies was stronger for approachers $(n=12)$ than for nonapproachers $(n=8$; Table 1 and Figure 4). The postplayback maximal frequencies were lower than preplayback ones in both approachers and nonapproachers, whereas the minimal frequencies were lower before playback than after playback but only for approachers (Table 2 and Figure 4). Additionally, birds with lower minimal frequencies before the playback were more likely to approach the speaker; however, this difference was marginally insignificant $(P=0.064$; Figure 4). The time between the lowest and peak frequencies of G2 was affected neither by the playback nor by the bird's behavior, whereas the change in peak frequency differed between approachers and nonapproachers (Table 2 and Figure 4). Thus, after the playback, the calls produced by 

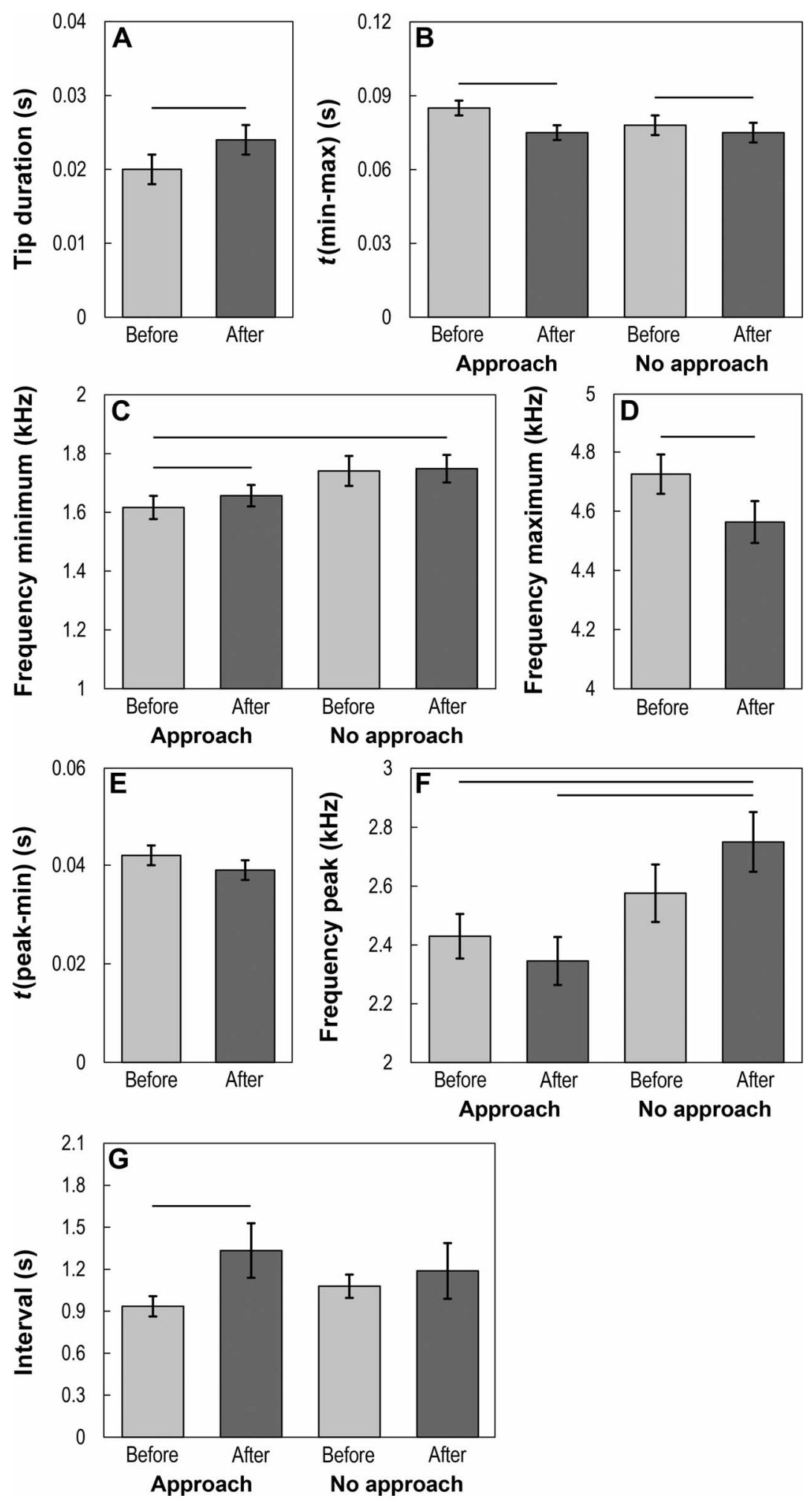

FIGURE 4. Variability of 7 structural and temporal parameters of whitt calls in relation to experimental stage (before [light gray] or after [dark gray] playback) and tactic (approach vs. no approach after playback) among 26 male Spotted Crakes recorded in May, 2014, in Kampinoski National Park, Poland, and surrounding areas. Error bars represent SE. Significant differences are indicated by thick black lines. The factors were chosen according to the best model for each variable (see text and Table 2). For definitions of parameters, see Table 1. 
TABLE 2. Mixed-effect models testing the effect of playback and tactic used on 7 structural and temporal parameters of whitt calls of 26 male Spotted Crakes recorded in May, 2014, in Kampinoski National Park, Poland, and surrounding areas. The factors (stage: before or after playback; approach: yes or no) were chosen according to the AIC value of the models.

\begin{tabular}{|c|c|c|c|c|}
\hline Variable & Factor & df & $F$ & $P$ \\
\hline \multirow[t]{2}{*}{ Tip duration } & Intercept & 24.63 & 139.77 & $<0.001$ \\
\hline & Playback & 20.01 & 8.63 & 0.008 \\
\hline \multirow[t]{4}{*}{$t(\min -\max )$} & Intercept & 24.07 & $1,025.02$ & $<0.001$ \\
\hline & Playback & 21.10 & 98.06 & $<0.001$ \\
\hline & Approach & 24.07 & 0.45 & 0.510 \\
\hline & Playback*approach & 21.10 & 30.26 & $<0.001$ \\
\hline \multirow[t]{4}{*}{ Freq. min. } & Intercept & 24.03 & 3025.45 & $<0.001$ \\
\hline & Playback & 21.48 & 9.98 & 0.005 \\
\hline & Approach & 24.03 & 3.09 & 0.091 \\
\hline & Playback*approach & 21.49 & 4.64 & 0.043 \\
\hline \multirow[t]{2}{*}{ Freq. max. } & Intercept & 24.49 & $5,885.34$ & $<0.001$ \\
\hline & Playback & 21.83 & 6.28 & 0.020 \\
\hline \multirow[t]{2}{*}{$t($ peak-min $)$} & Intercept & 23.20 & 629.53 & $<0.001$ \\
\hline & Playback & 22.83 & 0.76 & 0.391 \\
\hline \multirow[t]{4}{*}{ Freq. peak } & Intercept & 22.84 & $2,013.97$ & $<0.001$ \\
\hline & Playback & 20.20 & 0.59 & 0.451 \\
\hline & Approach & 22.84 & 6.00 & 0.022 \\
\hline & Playback*approach & 20.20 & 4.82 & 0.040 \\
\hline \multirow[t]{4}{*}{ Interval } & Intercept & 19.39 & 86.85 & $<0.001$ \\
\hline & Playback & 18.49 & 3.79 & 0.067 \\
\hline & Approach & 123.62 & 0.0001 & 0.992 \\
\hline & Playback*approach & 58.40 & 4.38 & 0.041 \\
\hline
\end{tabular}

the birds in the first group had significantly lower peak frequencies (Figure 4). Finally, after the playback, the birds called with longer between-call intervals; however, this difference was significant only for approachers (Table 2 and Figure 4).

\section{Potential for Individual Recognition}

Despite changes in vocalizations in response to the playback, certain acoustic parameters retained a high potential for individual recognition. In this analysis, the same structural variables with data points collected from the 20 males, before and after the playback, were used as discriminating variables for individuals. The first 6 discriminant functions in the analysis were used because of their effect sizes; however, nearly all of the variance explained by the model was explained by the first 3 discriminant functions (Table 3). All the discriminating variables contributed significantly to the discrimination (Table 4), and $90 \%$ of the data points were properly classified to the individuals. The minimal frequency of G2 was the stronger and the only significant predictor of the first discriminant function, whereas tip duration and time between the lowest and highest frequencies of G2 were the strongest predictors of the second and third discriminant functions (Table 4). If the remaining variables were excluded from the analysis, these 3 variables classified $78.2 \%$ of the data points correctly.
TABLE 3. Discriminant functions with respective effect sizes for calls of 26 male Spotted Crakes recorded in May, 2014, in Kampinoski National Park, Poland, and surrounding areas.

\begin{tabular}{lccc}
\hline $\begin{array}{l}\text { Discriminant } \\
\text { function }\end{array}$ & Eigenvalue & $\begin{array}{c}\text { Percent of } \\
\text { variance }\end{array}$ & $\begin{array}{c}\text { Canonical } \\
\text { correlation }\end{array}$ \\
\hline 1 & 26.569 & 68.3 & 0.982 \\
2 & 5.838 & 15.0 & 0.924 \\
3 & 4.627 & 11.9 & 0.907 \\
4 & 1.291 & 3.3 & 0.751 \\
5 & 0.380 & 1.0 & 0.525 \\
6 & 0.166 & 0.4 & 0.378 \\
\hline
\end{tabular}

\section{DISCUSSION}

Even with a small repertoire of innately programmed vocalizations, the Spotted Crakes modified their calling to yield a substantial increase in the diversity of signals produced. In addition to loud whitt vocalizations, which were produced by all males, and soft rumble calls, which were produced only by aggressive males, whitt calls with 1 of 2 fundamental frequencies muted signaled different responses to playback. Moreover, the acoustic structure of whitt calls varied with reference to the simulated intrusion, the tactic used, or both. However, certain acoustic parameters retained a high potential for individual recognition despite changes in acoustic characteristics during playback. Males lengthened their between-call intervals as they approached the speaker, which suggests that there was a link between the temporal distribution of calls and the aggressive motivation of the males.

The main observation of the present study is the specific ability of birds to mute 1 of 2 fundamental frequencies in the whitt calls ( $\mathrm{F}+\mathrm{G}$ calls) depending on the tactic used. This suggests that muted $G$ or $F$ fundamentals signal different levels of aggression in response to simulated intrusion. Spotted Crakes that muted the F fundamental of the whitt call and used only G calls remained in a similar location during an intrusion. To a bystander listening to the territory owner from a distance of a few hundred meters, such a change would be imperceptible, but a nearby intruder might recognize such a change as a signal of submissiveness. By contrast, responders that either completely muted the $\mathrm{G}$ fundamental to create soft $\mathrm{F}$ calls or muffled the $\mathrm{G}$ fundamental to create muffled whitt calls approached the playback speaker. Consequently, aggressive responders produced several different types of soft calls, which are common aggressive signals among birds (Titus 1998, Anderson et al. 2008, Osiejuk 2011, Ręk and Osiejuk 2011).

To produce F calls, the Spotted Crakes amplified the effect of the soft $\mathrm{F}$ fundamental by removing the masking effect of the louder $\mathrm{G}$ fundamental. This conclusion is based on a comparison of $\mathrm{F}+\mathrm{G}$ calls, muffled whitt calls, and F calls, in which the muffled whitt calls were not 
TABLE 4. Correlations between discriminating variables and discriminant functions for calls of 26 male Spotted Crakes recorded in May, 2014, in Kampinoski National Park, Poland, and surrounding areas.

\begin{tabular}{|c|c|c|c|c|c|c|}
\hline \multirow[b]{2}{*}{ Discriminating variable } & \multicolumn{6}{|c|}{ Discriminant function } \\
\hline & 1 & 2 & 3 & 4 & 5 & 6 \\
\hline$\chi^{2}$ & $3,507.35$ & $2,101.08$ & $1,285.92$ & 553.45 & 201.93 & 65.23 \\
\hline df & 138 & 110 & 84 & 60 & 38 & 18 \\
\hline$P$ & $<0.001$ & $<0.001$ & $<0.001$ & $<0.001$ & $<0.001$ & $<0.001$ \\
\hline Freq. min. & 0.833 & -0.210 & 0.404 & -0.287 & -0.118 & -0.061 \\
\hline Tip duration & 0.066 & 0.445 & 0.866 & 0.108 & -0.182 & -0.052 \\
\hline$t(\min -\max )$ & 0.124 & 0.598 & -0.668 & 0.289 & 0.240 & -0.200 \\
\hline Freq. peak & 0.112 & -0.232 & 0.130 & 0.846 & 0.247 & -0.373 \\
\hline Freq. max. & 0.204 & 0.199 & -0.228 & 0.579 & -0.531 & 0.500 \\
\hline$t($ peak-min) & 0.085 & -0.082 & -0.082 & 0.502 & 0.720 & 0.456 \\
\hline
\end{tabular}

Notes: The variables that loaded highest in each function are shown in bold. A chi-square test was used to evaluate the hypothesis that the means of the variables were equal across individuals.

simple intermediate sounds between the other 2 types of calls. Only the G fundamental in the muffled whitt calls was softened, and the $\mathrm{F}$ fundamental was not affected, which suggests that the muting of the G fundamental was intentional and was aimed at the amplification of the effect of the F fundamental. If the acoustic structure of $\mathrm{F}$ calls or rumble calls was compared with $\mathrm{G}$ calls, the choice of the vocalization for aggressive signaling was not a simple decision between a soft and loud signal but also involved a decision between a high- and a low-frequency signal. Moreover, in the Corn Crake, the maximum limit for communication distance with soft calls was significantly shorter than that of loud calls, if played at the same amplitude, which suggests that the acoustic structure of soft vocalizations was used to limit the range of the signal (Ręk 2013b). Consequently, these results are consistent with a previous report that suggested that soft vocalizations are something more than low-amplitude signals (Ręk 2013b, 2014).

Thus far, the 3 major categories of soft vocalizations have been described as follows: structurally distinct soft vocalizations, low-amplitude variants of normal vocalizations, and normal vocalizations with additional lowamplitude components (for a review, see Searcy et al. 2014). Rumble calls match the first category, and muffled whitt calls might be assigned to the second category; however, the production of the clear $\mathrm{F}$ call through the selective muting of the $G$ fundamental did not fall into any of the categories. Consequently, this study extends our knowledge of the diversity of acoustic aggressive signaling.

In addition to the diversity of calls, the Spotted Crake's $\mathrm{F}+\mathrm{G}$ and $\mathrm{G}$ calls were characterized by a substantial variability of acoustic parameters and temporal distributions. The results showed that approachers were recruited predominantly from those birds that called with lower minimal frequency before the playback and that such birds additionally decreased the peak frequency after the playback. Because of inherent constraints on soundproduction mechanisms, sounds with lower frequencies are generally easier for larger individuals to produce (Ryan and Brenowitz 1985, Fletcher 2007). Hence, the higher level of aggressiveness among males calling with lower frequencies might be justified (Price et al. 2006). Additionally, the time between the lowest and highest frequencies of G2 shortened more in the calls of approachers. Generally, this type of change was a consequence of the decreased maximal frequency of G2 after the playback. In approachers, it was additionally intensified because of the slightly higher minimal frequency of G2 after the playback (Figure 4). Nevertheless, these changes could also be associated with changes in the length of between-call intervals and in the pattern of the temporal distribution of calls.

Approachers lengthened the between-call intervals after the playback, which suggests that aggressive males use temporal distribution of calls to signal their aggressive motivation. In terms of mating signals, this behavior might seem counterintuitive because the opposite might be expected, with high-quality males producing calls at higher rates (Baker et al. 2012). Perhaps more aggressive males lengthened the intervals between calls to increase their ability to locate the intruder. Nevertheless, this phenomenon might also be explained by comparison with the Corn Crake, in which males also lengthened the intervals between calls. However, the Corn Crakes did it without any apparent practical reason or advantage. In the Corn Crake, it was a specific convention and, most likely, a culturally transmitted signaling system that encoded information about the sender's aggressive motivation (Ręk 2013a, Ręk and Osiejuk 2013). The possibility of a similar system in a closely related species suggests that the mechanism of arbitrary temporal coding is a specific ancestral characteristic in the Rallidae. 
Spotted Crakes might use several of the structural parameters of $\mathrm{F}+\mathrm{G}$ and $\mathrm{G}$ calls for individual recognition. The time between the lowest and highest frequencies of G2, lowest frequency of G2, and tip duration had the highest inter-individual variations. Surprisingly, such variation among individuals was maintained even when males were subjected to playback. This result was surprising for the first 2 parameters because they changed significantly with the tactic used, which strongly suggested that males used them purposefully. Nevertheless, these 2 functions did not necessarily exclude one another, even though they might be temporarily at odds. First, the calls were complex in structure and varied in features that were not included in the discussed function. The whitt calls, with multiple harmonics, emphasized formant bands of frequencies, and biphonation resembled mammalian vocalizations; such "mammalian" characteristics have been found to be useful in individual recognition (Tooze et al. 1990, Budka and Osiejuk 2013a). Second, the density of Spotted Crakes was most often extremely low, and males did not have to recognize many conspecifics at a time. Third, the birds produced long sequences of calls that could be heard from $>2 \mathrm{~km}$ away (Cramp and Simmons 1980); therefore, they had ample opportunity to learn. Despite the dissimilarities between the calls of Spotted Crakes and Corn Crakes, it appears that Spotted Crake calls had a satisfactory potential for individual recognition.

\section{ACKNOWLEDGMENTS}

I thank R. Magrath for valuable comments on the manuscript. The study was conducted thanks to permission given by Director of Kampinoski National Park (DE0604/6/14).

Funding statement: The work was supported by the National Science Centre (grant no. UMO-2011/03/D/NZ8/02133). During the study, I was supported by the "Mobility Plus" program of the Ministry of Science and Higher Education in Poland to the Australian National University.

Ethics statement: The use of animals in this study adhered to ethical guidelines for animal research in Poland as well as all the institutional guidelines of the Adam Mickiewicz University.

\section{LITERATURE CITED}

Anderson, R. C., W. A. Searcy, M. Hughes, and S. Nowicki (2012). The receiver-dependent cost of soft song: A signal of aggressive intent in songbirds. Animal Behaviour 83:14431448.

Anderson, R. C., W. A. Searcy, S. Peters, and S. Nowicki (2008). Soft song in Song Sparrows: Acoustic structure and implications for signal function. Ethology 114:662-676.

Baker, T. M., D. R. Wilson, and D. J. Mennill (2012). Vocal signals predict attack during aggressive interactions in Black-capped Chickadees. Animal Behaviour 84:965-974.
Beecher, M. D., P. K. Stoddard, S. E. Campbell, and C. L. Horning (1996). Repertoire matching between neighbouring Song Sparrows. Animal Behaviour 51:917-923.

Brumm, H., and M. Ritschard (2011). Song amplitude affects territorial aggression of male receivers in chaffinches. Behavioral Ecology 22:310-316.

Budka, M., and T. S. Osiejuk (2013a). Formant frequencies are acoustic cues to caller discrimination and are a weak indicator of the body size of Corncrake males. Ethology 119:960-969.

Budka, M., and T. S. Osiejuk (2013b). Neighbour-stranger call discrimination in a nocturnal rail species, the Corncrake Crex crex. Journal of Ornithology 154:685-694.

Cramp, S., and K. E. L. Simmons (Editors) (1980). Birds of the Western Palearctic. Oxford University Press, Oxford, UK.

Dabelsteen, T., P. K. McGregor, H. M. Lampe, N. E. Langmore, and J. Holland (1998). Quiet song in song birds: An overlooked phenomenon. Bioacoustics 9:89-105.

Dabelsteen, T., and S. B. Pedersen (1990). Song information about aggressive responses of blackbirds, Turdus merula: Evidence from interactive playback experiments with territory owners. Animal Behaviour 40:1158-1168.

Darolová, A., J. Krištofík, H. Hoi, and M. Wink (2012). Song complexity in male Marsh Warblers: Does it reflect male quality? Journal of Ornithology 153:431-439.

Evans, C. S., and L. Evans (2007). Representational signalling in birds. Biology Letters 3:8-11.

Fletcher, N. (2007). Animal bioacoustics. In Springer Handbook of Acoustics (T. D. Rossing, Editor). Springer, New York, NY, USA. pp. 785-804.

Foote, J. R., L. P. Fitzsimmons, D. J. Mennill, and L. M. Ratcliffe (2008). Male chickadees match neighbors interactively at dawn: Support for the social dynamics hypothesis. Behavioral Ecology 19:1192-1199.

Freeberg, T. M., and J. R. Lucas (2002). Receivers respond differently to chick-a-dee calls varying in note composition in Carolina Chickadees, Poecile carolinensis. Animal Behaviour 63:837-845.

Griesser, M. (2008). Referential calls signal predator behavior in a group-living bird species. Current Biology 18:69-73.

Hof, D., and N. Hazlett (2010). Low-amplitude song predicts attack in a North American wood warbler. Animal Behaviour 80:821-828.

Janik, V. M., and P. J. B. Slater (2000). The different roles of social learning in vocal communication. Animal Behaviour 60:1-11.

Livezey, B. C. (1998). A phylogenetic analysis of the Gruiformes (Aves) based on morphological characters, with an emphasis on the rails (Rallidae). Philosophical Transactions of the Royal Society of London, Series B 353:2077-2151.

Osiejuk, T. S. (2011). Soft song and the readiness hypothesis: Comments on Akçay et al. (2011). Animal Behaviour 82:e1e3.

Osiejuk, T. S. (2014). Differences in frequency of shared song types enables neighbour-stranger discrimination in a songbird species with small song repertoire. Ethology 120:893903.

Price, J. J., S. M. Earnshaw, and M. S. Webster (2006). Montezuma Oropendolas modify a component of song constrained by body size during vocal contests. Animal Behaviour 71:799807. 
Ręk, P. (2013a). Corncrake males learn new signal meanings during aggressive interactions. Animal Behaviour 86:451-457.

Ręk, P. (2013b). Soft calls and broadcast calls in the Corncrake as adaptations to short and long range communication. Behavioural Processes 99:121-129.

Ręk, P. (2014). Do aggressive signals evolve towards higher reliability or lower costs of assessment? Journal of Evolutionary Biology 27:2605-2613.

Ręk, P., and T. S. Osiejuk (2010). Sophistication and simplicity: Conventional communication in a rudimentary system. Behavioral Ecology 21:1203-1210.

Ręk, P., and T. S. Osiejuk (2011). Nonpasserine bird produces soft calls and pays retaliation cost. Behavioral Ecology 22:657662.

Ręk, P., and T. S. Osiejuk (2013). Temporal patterns of broadcast calls in the Corncrake encode information arbitrarily. Behavioral Ecology 24:547-552.

Ryan, M. J., and E. A. Brenowitz (1985). The role of body size, phylogeny, and ambient noise in the evolution of bird song. American Naturalist 126:87-100.
Searcy, W. A., Ç. Akçay, S. Nowicki, and M. D. Beecher (2014). Aggressive signaling in Song Sparrows and other songbirds. Advances in the Study of Behavior 46:89-125.

Searcy, W. A., S. Nowicki, and S. Peters (1999). Song types as fundamental units in vocal repertoires. Animal Behaviour 58: 37-44.

Slabbekoorn, H., and C. ten Cate (1998). Multiple parameters in the territorial coo of the Collared Dove: Interactions and meaning. Behaviour 135:879-895.

ten Cate, C. (2004). Birdsong and evolution. In Nature's Music: The Science of Birdsong (P. Marler and H. Slabbekoorn, Editors). Elsevier Academic Press, San Diego, CA, USA. pp. 296-317.

Titus, R. C. (1998). Short-range and long-range songs: Use of two acoustically distinct song classes by Dark-eyed Juncos. The Auk 115:386-393.

Tooze, Z. J., F. H. Harrington, and J. C. Fentress (1990). Individually distinct vocalizations in timber wolves, Canis lupus. Animal Behaviour 40:723-730. 